\title{
Greening is not a priority for human resource: Insights from human resource practitioners
}

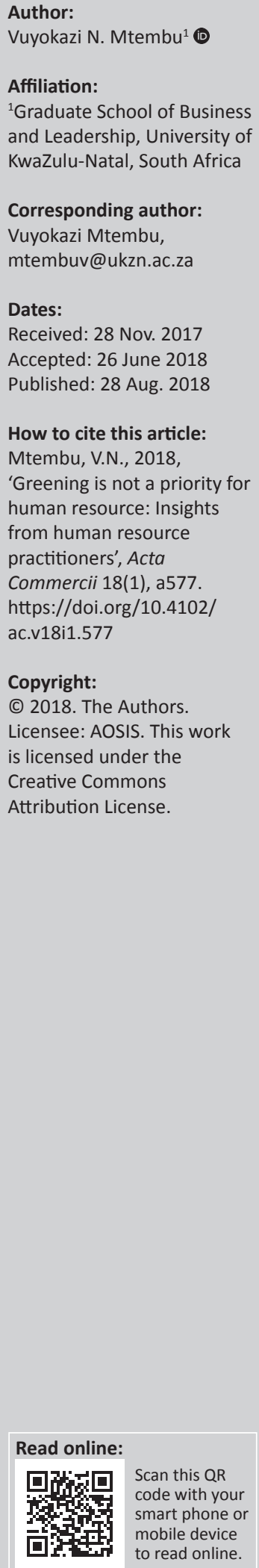

Orientation: In the 21st century, human resource (HR) practitioners are expected to be agile, transformative and environmentally conscious. HR operations are required to be aligned with the current environmental trends to ensure business sustainability and profitability.

Research purpose: The aim of this study is to determine whether the implementation of green human resource management (HRM) practices in organisations is a priority or not, and also to investigate the perceptions of HR practitioners on the implementation of green HRM in organisations.

Motivation for the study: Although green HRM studies have been conducted on various continents, there is a paucity of information on green HRM on the African continent. The researcher was motivated to investigate the status of green HRM in the African context considering socio-economic development challenges and other pressing priorities that developing African countries and organisations are facing.

Research design, approach and method: Qualitative research method was employed in the study. Twenty human resource managers and senior practitioners from higher education institutions formed the population interviewed. Thematic analysis was used to analyse the data collected.

Main findings: Results revealed that the majority of HR practitioners have a perception that greening activities should not be in a list of priorities for the HR division. The results also revealed that HR practitioners are not experts on greening issues and that there were no green HR policies in the institutions surveyed. As a result, the HR division plays little to no role in greening initiatives within the institutions.

Practical/managerial implications: Information from the study can be used to advise managers and HR policymakers on the importance of infusing an environmental sustainability concept in HR policies, and also on how green HRM can be implemented effectively within organisations.

Contribution/value-add: This study extends green HRM discourse by investigating the importance of green HRM implementation in an African institution.

\section{Introduction}

South Africa, known as a rainbow nation to its beloved people, is a beautiful and colourful land of many contrasts, with a mix of both developed and developing world characteristics. It is a country where green and beautiful jungles with wild animals coexist in close proximity with modern cities and where the protection of the environment by government, industry and citizens is hailed in the constitution and in different sector policies and legislation. Public and private sector organisations, through legislation, interest groups' pressure and pressures from society in general, are expected to abide by the three pillars of sustainability - compliance, governance and ethics - which serve as a solid platform for the development of a sustainability conscious nation. Everyone is expected to contribute towards environmental protection and doing right as far as conservation of natural resources is concerned. Hence, the country in the last decade has seen both government and private industries trying to play a role towards greening efforts within and outside their organisations.

Green human resource management (HRM) looks at the role that the human resource (HR) division plays in assisting organisations to adopt green lifestyles, by being environmentally aware, resource efficient and sustainable (Mandip 2012). In the 21st century, HR practitioners need to be agile, transformative and align themselves with the current trends to ensure 
business sustainability and profitability. Higher education institutions with their power and potential to educate, influence and change the nation's thinking and behaviour can make an invaluable contribution to the fight against resource depletion and to minimise climate change's negative effects on societies (Niu, Jiang \& Li 2010; Yuan, Zuo \& Huising 2013). Higher education institutions have a profound moral responsibility to increase the awareness, knowledge, skills and values needed to create a just and sustainable future; they prepare most of the professionals who develop, lead, manage, teach, work in and influence society's institutions (Niu et al. 2010; Yuan et al. 2013). A number of scholars in green HRM have asserted that the HR division as a strategic partner in the organisation can play an influential role towards the efficient use of resource in organisations (Prasad 2013; Strandberg 2009). Although scholars have argued that HR can play a valuable role in greening organisations (Mandip 2012; Prasad 2013; Strandberg 2009), research has established that most HR practitioners are very complacent to involve themselves in initiatives to save natural resources within their organisations (Ahmad 2015; Cherian \& Jacob 2012; Dutta 2012; Shatouri, Omar \& Igusa 2012). This then poses a question as to why some HR practitioners avoid being part of green initiatives in organisations. This article attempts to query the underlying motives for this ignorance and resistance in some cases by interrogating how HR practitioners view the importance of green HRM in organisations.

In their review article on green HRM research and contemporary developments in the field for the last two decades (1996-2016), Renwick et al. (2016) reveal that HR scholars are undertaking serious discussions that may extend global debates on the HRM role in reducing ecological degradation. This study extends that discourse by looking at the question whether greening is a priority or not in HR divisions of a developing country facing many other pressing priorities. Furthermore, this article broadens the narrative of green HRM by asking the question whether the implementation of green HRM is important or not and whether it is a priority considering the challenges of poverty, and socio-economic development and other pressing priorities of African countries and organisations.

\section{Literature review}

\section{Perceptions of human resource practitioners on the importance of green human resource management}

It is a common sentiment for the majority of HR scholars and practitioners that $\mathrm{HR}$ division can play a significant and central role in creating a culture of sustainability within organisations. An organisation's HR function can be instrumental in facilitating a comprehensive approach to creating a culture of sustainability and environmental stewardship (Leibowitz 2010). 'HR function is critical to achieving success in a sustainability-driven organisation'
(Cohen, Taylor \& Carmen 2012:1). Cohen et al. (2012) furthermore states that:

sustainability practice needs to be embedded across an organisation at all levels, becoming an ongoing change process, since the prime focus and skills of HR professionals include organisational process, change management and culture stewardship, HR should take a leading role in developing and implementing a sustainability strategy. (p. 1)

Eisenstat concurs that HR has a central role to play in organisational sustainability by stating that the HR division can stimulate the inclusion of issues concerning sustainability in the scope of the various relationships that take place inside a company and with external organisations (Jabbour \& Santos 2008).

This study attempts to probe the reasons why HR is not fully committed on greening efforts in organisations. This will be done by investigating the perceptions of HR practitioners towards green HRM, implementing green HRM practices within the institutions surveyed and exploring the priorities of the HR division, and specifically by investigating if greening initiatives are part of the HR division priorities or not.

\section{Theoretical framework: Schein's organisational culture theory}

Organisational culture theory is a theoretical base that underpins this study and a point of departure in the same. Organisational culture theory helps us to understand the kind of vision, beliefs, values, principles, behaviours and goals an institution requires in embedding a culture of sustainability, which is why this theory fits well in the context of this article. Schein (2004:12) defines culture as a 'pattern of shared basic assumptions that is learned by a group as it solved its problems of external adaptation and internal integration'. He continues to state that these basic assumptions should work well enough to be considered valid and therefore to be taught to new members as the correct way to perceive, think and feel in relation to those problems (Schein 2004:12). Organisational culture reflects the identity of the organisation and how things are done within it. Culture is embedded in the values, norms, practices, attitudes, behaviours and even the infrastructure of the organisation. Culture forms the identity of the organisation as well as that of people working for that organisation. Schein's (2004) mainstream organisational culture theory provides a great foundation in the exploration of how organisational culture can be established towards being conducive for green and sustainable operations as it provides the building blocks for the foundation of a strong organisational culture. Those building blocks are assumptions and beliefs, espoused values and artefacts.

The question whether green HRM practice is important or a priority in the organisation will be non-existent if it was naturally in the DNA and culture of organisations to conserve resources. In any given organisation, if every employee's desire is to work for a green organisation and their attitudes, 
feelings and behaviours are all aligned towards natural resource conservation, resistance towards greening initiatives will be an unknown phenomenon. If natural resource conservation was embedded in the belief systems, values, artefacts and infrastructure of the organisation, there will be no question whether greening is a priority or not as conservation will be a natural thing for organisations to do. Employee resistance of green practices will not even be of concern as greening and the organisation will be one, not isolated from each other.

The HR division can be instrumental in facilitating a comprehensive approach for creating a culture of sustainability and environmental stewardship (Leibowitz 2010). 'As such, in many successful organisations, the HR Department is the keeper of the culture' (Leibowitz 2010:51).

The HR division possesses knowledge and skills to take the organisation's mission, vision, and values, to reinforce a strong, values-driven organisational culture with their many human resource systems, such an approach has been implemented successfully in many companies that wanted to create, for example, a total quality culture. (Ulrich 1998 cited in Leibowitz 2010)

Therefore, one can argue that with HR employing the building blocks which are explicitly laid out in Schein's (2004) organisational theory culture, they can build an organisational culture that is conducive to conservation of natural resources and whose identity is synonymous with the term 'greening organisation'. Therefore, the argument here is that: the organisation's culture plays a prominent role in the quest to achieve green and sustainable organisations. It is the foundation and building blocks from which employee's behaviours are shaped, and it influences and guides operations within the organisations. Culture therefore plays a vital role in the realisation of green organisations. The question of whether greening is a priority or not for HR will not exist if green culture was the lifestyle in every workplace or company. Realising that it is not the case in most organisations with different functions within organisations shifting and tossing the greening responsibility to others, it became necessary to investigate what are the perceptions and attitudes of each function within the organisation towards greening; hence, this article's focus is on the HR function, which is one of the key functions within the organisation.

\section{Methodology}

The study followed a qualitative research approach. Twenty HR managers and senior practitioners from higher education institutions in KwaZulu-Natal, South Africa, were sampled through purposive sampling method, and they formed the population surveyed in the study. Sample included males and females belonging to African, Indian and white ethnicities aged between 32 and 56 years with more than 5 years' experience working in HR industry. Practitioners strategically placed within the HR division such as senior HR practitioners and managers were the main target group for the interviews. This meant that people with more practical insight not only in HR practice but also in policy formulation and in a broader scope of HR activities from planning phase to implementation stages were selected and interviewed. The interview schedule consisting of 19 open-ended questions was employed in data collection; this allowed the participants to elaborate, substantiate and explain their responses freely without much restriction. Human resource practitioners were asked questions on their understanding of green HRM concept, green HRM policies, implementation, benefits, challenges and perceptions within their organisations. The interview schedule was designed in such a way that the interviews took between 45 and $60 \mathrm{~min}$ each to complete. Thematic analysis was used to analyse the data collected. The purpose of thematic analysis was to identify patterns of meaning across the data set in order to provide an answer to the research question. Patterns were identified through a rigorous process of data familiarisation, data coding and theme development. Data were divided into categories, subcategories, perspectives and themes and were analysed to determine findings. The collected data were then analysed and interpreted in to draw meaningful conclusions and to identify important patterns and relationships. To ensure trustworthiness and rigour, the researcher employed Guba (1981) four measures: truth value, applicability, consistency and neutrality, also to ensure credibility, reliability, applicability and objectivity and to avoid researcher bias on the findings presented.

\section{Ethical considerations}

Ethical clearance for the study was received from the University of KwaZulu-Natal (ethics clearance protocol reference number: HSS/0401/016D).

\section{Results}

The following themes emerged from the interviews:

\section{Greening is not a priority for the human resource division}

The sentiment among the majority of participants was that green initiatives within organisations are not the responsibility nor a priority for the HR division. The key reasons they stated were that HR division is overwhelmed with too much responsibility and HR practitioners are not experts in environmental sustainability. In their own words, one participant stated the following:

'Greening is not a priority for HR division, recruiting the right amount of people with the right skills and retaining them to ensure that the organisation achieves its key and core mandate is an HR priority.' (Participant 4, female, 48)

\section{Another participant stated that:}

'Our job is already too much and too complicated, especially as HR Practitioners serving higher education institutions in South Africa, with the transformation and changes taking place in this sector, we are already overwhelmed and overburdened.' (Participant 7, male, 49) 
The same views, expressions and feelings were voiced out throughout all interviews and questions in the study. The majority of managers interviewed expressed a view that taking on greening projects will be biting off more than they can chew and they settled on the opinion that it will do them most good to focus more on their core HR functions leaving greening initiatives to environmental specialists.

\section{There are no green human resource management policies and strategies}

Here the interviewer wanted to find out if there were institutional and HR divisional policies and strategies that talk to greening of the institution. All participants mentioned that there was nothing about greening and saving of resources in the HR policies that they implement on a daily basis in their institutions. There were a couple of participants who stated that they believed that resource efficiency and greening issues are not explicitly stated in $\mathrm{HR}$ and institutional policies and operational strategies as there is a tacit belief that saving resources is something that people should know and do in general. A participant in her words stated that:

'Assumption is that employees are aware of the standards that the institution has to use resources efficiently, they should know to use resources efficiently, which is a very ignorant assumption in this instance as it's not always the case.' (Participant 5, female, 47)

Another participant added more reasons why higher education institutions do not focus much on having green policies and strategies to drive their activities as he said that public sector institutions' decisions are not driven mainly by cost efficiency and profits, as it is the case in the private sector. In his own words he stated that:

'Private sector are trendsetters on green issues and policies, public sector always follow far behind as they draw energy from private sector.' (Participant 8, male, 49)

In a study that surveyed 147 UK firms, $77 \%$ of firms surveyed were found to have an environmental policy in place within their organisation and fewer than $45 \%$ of organisations had integrated environmental concerns in their organisational vision or mission statement. This was found to be the most common means of encouraging staff to behave in a pro-environmental way (Bartlett 2011). Out of the three universities surveyed in this particular research, the researcher was able to find that two of the institutions have environmental policies in place and one institution has green clauses in its strategic operational plan. This does correlate with the UK study findings and it indicates that top level management of these institutions are aware of the need to adopt green practices in their institutions because they have drafted environmental policies in this regard. One question that one will now ask is, why is there no effective implementation of the environmental policy? As much as this question is a bit out of the focus for this study which mainly focused on the HR division rather than the organisation as a whole, its answer will help to clarify the position of all managers at all levels and divisions of the organisation. In an attempt to answer it, one will conclude that there is not much pressure both internally and externally that forces managers to ensure full and effective application of policy. Policies are drafted just for compliance reasons and filed in cabinets without any implementation and follow-up. There are also no policy enforcement measures in place. These findings are consistent with the study by Harris and Crane (2002) who found that, while most managers are aware of green pressures, few organisations respond with the level of enthusiasm hoped for by green activists. Harris and Crane (2002) also found that macro-environmental pressures on organisations were presently insufficient to require anything more than superficial statements of policy. In this particular study, in the three universities surveyed, HR practitioners were not aware of these environmental policies in their institution, which is a worrying factor in this instance, as it indicates either ignorance or a lack of awareness on their part. HR managers' or practitioners' lack of knowledge on greening and resource efficiency policies and activities taking place within their institutions is of major concern as it gives the impression that HR employees only focus on policies that affect their specific division. This is very concerning especially because HR is a shared services department and its services have an impact in the entire organisation and its employees.

\section{Greening does not fall under the human resource division mandate}

Literature has revealed that HR practitioners have the perception that environmental sustainability activities in organisations are for other divisions such as production or operations divisions, but not HR (Daily \& Huang 2001; Jabbour \& Santos 2008; Liebowitz 2010). Therefore, HRM division tends to distance itself from any environmental sustainability efforts within the organisation (Daily \& Huang 2001; Jabbour \& Santos 2008; Liebowitz 2010). Findings uncovered that the majority of HR practitioners view greening and environmental sustainability issues as not the responsibility of HR. Majority of interviewees stated that HR practitioners are not experts on green efficiency issues. As a result, some participants felt that there would have to be a separate unit set up within HR where new people consisting of both HR and environmental or greening specialists will drive these green initiatives within the division and institution. This perception is consistent with studies from other countries including India, Brazil, the United States, Saudi Arabia and others. They also found that the HR division perceives environmental sustainability activities in organisations as responsibilities for other divisions such as production, marketing or operations (Ahmad 2015; Daily \& Huang 2001; Dutta 2012; Jabbour \& Santos 2008; Jacob \& Cherian 2012; Liebowitz 2010; Prasad 2013; Shatouri et al. 2012). As a consequence of this perception, HR tends to distance themselves from any environmental sustainability efforts within the organisation. 


\section{Human resource division has sufficient core responsibilities}

The majority of managers interviewed stated that HR division is overburdened with work in the form of core HR activities. They further voiced that an additional function focusing on green issues would stretch the divisional responsibility to a point of exhaustion leading to ineffectiveness in their principal duties. One interviewee mentioned:

'With the role of HR division evolving and expanding every day, it will be unfair for the institution to give HR Practitioners more functions over and above what they already juggling with.' (Participant 9, female, 38)

Another interviewee mentioned that:

'Our job is already too much and too complicated, therefore it will be unwise for us to take more work than we already have, we will be biting more than we can chew.' (Participant 8 , male, 49)

Another participant stated that:

'Establishing green culture within the institution is not an HR only responsibility, it will require a collective effort from all employees, all levels, all departments and executive management support in order for it to be a success.' (Participant 3, female, 47)

Overall, most HR managers expressed a view that, with HR having so many activities within their job scope, greening activity is not anywhere in the list of priorities for their division.

\section{Human resource practitioners are not experts on green efficiency issues}

Most interviewees explicitly stated that HR practitioners are not experts in environmental conservation and its related areas. They do not have adequate knowledge, skills capacity and even time to drive green projects within the organisation. As a result, some participants suggested that for organisations aspiring to 'go green' they must employ services of an environmental sustainability coordinator or set up a separate unit within HR where new people consisting of both HR and environmental or green specialists will have to be employed to drive organisational green initiatives. The common sentiment among all participants was that employing specialist personnel in the form of an experienced and competent environmental coordinator, who will be fully dedicated in driving green projects, will be a better solution in ensuring that the organisation achieves its greening ambitions. Also, most participants agreed that they would be willing to assist the coordinator on areas of training, awareness and culture change efforts.

\section{There are no green projects implemented by human resource division}

Asking HR practitioners to outline green projects the HR division is involved in at their institutions, the majority of participants mentioned that the HR division is not involved in any green projects in the organisation. When asked to give reasons for this lack of involvement in green projects by HR, one participant mentioned that:

'HR officials are extremely busy with their core activities of staffing, training, rewards managements and others, environment management is not in our core duties.' (Participant 8, Male, 49)

Another participant shared the same sentiment by stating that:

'Greening is not in our job descriptions, we were not employed here to do green projects, our work is to look after the needs of our employees, to ensure that they are taken care of, they are productive and retained.' (Participant 6, Male, 35)

\section{Discussion of findings}

The results in this study have indicated that HR divisions have not yet embraced the greening role, and they refuse to take its ownership. There is still majority of practitioners whose perceptions and sentiments believe that 'greening and environmental efficiency' roles are not for HR. Over and above these sentiments, there are also challenges for green HRM in the institutions. Challenges such as absence of green HR policies in organisations, lack of financial support for green initiatives, lack of skills capacity for this area in HR, lack of management commitment, lack of staff buy-in and commitment and many more. There is a lot that needs to be done to bring the HR division on board in order for them to contribute to the realisation of green organisations. In summary, the study found that most HR practitioners perceive the greening role as being outside of their scope of work and not within their mandate. Some HR practitioners view the role as an additional burden to the already overburdened job description they have to deliver in their organisations. One other factor over and above the 'overload' factor that brings about hesitation from the HR community to embrace the sustainability role is the lack of expertise within HR on green-related skills and knowledge.

\section{Limitations of the study and directions for future research}

The study was restricted to higher education institutions. Ideally, green HRM landscape should have been studied in all sectors and in the whole of South Africa. However, because of various constraints, this was not feasible for the researcher. Therefore, the findings of this study cannot be generalised to all sectors; generalisation should be done with caution and with due consideration of a broad spectrum of factors that are unique to each sector. Future studies could also examine green HRM among all sectors in South Africa, with a view to undertaking a comparative analysis among sectors, provinces and even among other African countries and developing countries.

\section{Recommendations and conclusion}

This investigation has focused on probing the role, commitment and contribution of the HR division in the 
bigger movement of curbing ecological degradation and using natural resources efficiently to ensure green and sustainable organisations. It is evident that the HR division is still lagging behind in this movement with one of the main reasons being the fact that HR division is not fully convinced to take part in greening initiatives. To achieve green organisations with HR playing an instrumental role, the following will need to be in place: management commitment, drafting and installation of green HRM policies, creation of a green conscious culture within the organisations and education, and awareness, all these will be key requirements. Financial injection towards organisational green initiatives, upskilling and capacitating HR personnel on greening issues, staff buy-in and commitment will all be required for organisations to achieve green and sustainability status through green HRM.

\section{Acknowledgements Competing interests}

The author declares that she has no financial or personal relationships that may have inappropriately influenced her in writing this article.

\section{References}

Ahmad, S., 2015, 'Green human resource management: Policies and practices', Cogent Business and Management 2, 1-13. https://doi.org/10.1080/23311975.2015.10 30817

Bartlett, D., 2011, Going green: The psychology of sustainability in the workplace, The British Psychological Society, Leicester, UK.

Cherian, J. \& Jacob, J., 2012, 'A study of green HR practices and its effective implementation in the organization: A review', Canadian Center of Science and Education 7(21), 25. https://doi.org/10.5539/ijbm.v7n21p25
Cohen, E., Taylor, S. \& Camen, M., 2012, HRM's role in corporate social and environmental sustainability, SHRM Foundation, an affiliate of the Society for Human Resource Management, Alexandria, VA.

Daily, B. \& Huang, S., 2001, 'Achieving sustainability through attention to human resource factors in environment management', International Journal of Operations and Production Management 21(12), 1539-1552. https://doi.org/ 10.1108/01443570110410892

Dutta, S., 2012, 'Greening people: A strategic dimension', Zenith International Journal of Business Economics and Management Research 2(2), 143-148.

Guba, E.G., 1981, 'Criteria for assessing the trustworthiness of naturalistic inquiries', Educational Communication and Technology 29(2), 75-91.

Harris, L. \& Crane, A., 2002, 'The greening of organisational culture: Management views on the depth, degree and diffusion of change', Journal of Organisational Change Management 15(3), 214-234. https://doi.org/10.1108/09534810210429273

Jabbour, C.J.C. \& Santos, F.C.A., 2008, 'The central role of human resources in search for sustainable organisations', International Journal of Human Resource Management 19(12), 2133-2154. https://doi.org/10.1080/09585190802479389

Jackson, S.E. \& Seo, J., 2010, 'The greening of strategic HRM scholarship', Organisation Management Journal 7(4), 278-290. https://doi.org/10.1057/omj.2010.37

Leibowitz, J., 2010, 'The role of HR in achieving a sustainability culture', Journal of Sustainable Development 3(4), 51. https://doi.org/10.5539/jsd.v3n4p50

Mandip, G., 2012, 'Green HRM: People management commitment to environmental sustainability', Research Journal of Recent Sciences 2277, 2502.

Niu, D., Jiang, D. \& Li, F., 2010, 'Higher education for sustainable development in China', International Journal of Sustainability in Higher Education 11(2), 153-162. https://doi.org/10.1108/14676371011031874

Prasad, R.S., 2013, 'Green HRM-partner in sustainable competitive growth', Journal of Management Sciences and Technology 1(1), 15-18.

Renwick, D., Jabbour, C.J.C., Muller-Camen, M., Redman, T. \& Wilkinson, A., 2016, 'Contemporary developments in Green (environmental) HRM scholarship', The International Journal of Human Resource Management 27(2), 114-128. https:// doi.org/10.1080/09585192.2015.1105844

Schein, E., 2004, Organisational culture and leadership: A dynamic view, 3rd edn., Jossey-Bass, San Francisco CA.

Shatouri, M., Omar, R. \& Igusa, K., 2012, 'Towards a new era of sustainability in the automotive industry: Strategic human resource management and green technology innovation', World Academy of Science, Engineering and Technology 6, 9-22.

Strandberg, C., 2009, The role of human resource management in corporate social responsibility, Vancouver, Canada.

Ulrich, D., 1998, 'A new mandate for human resources', Harvard Business Review, January-February, 124-134

Yuan, X., Zuo, J. \& Huising, D., 2013, 'Green universities in China: What matters', Journa of Cleaner Production 61, 36-45. https://doi.org/10.1016/j.jclepro.2012.12.030 